\title{
Orthopaedic aspects of diabetic foot syndrome classifications
}

\author{
M.V. Parshikov, P.S. Bardiugov, N.V. Yarygin
}

A.I. Evdokimov Moscow State University of Medical and Dental, Moscow, Russian Federation

\begin{abstract}
Introduction For long, orthopedic approaches to the management of diabetic foot syndrome (DFS) remained underexplored in Russia. Deformities of the distal segments of lower extremities play a role in the pathogenesis of DFS. There are limitations and a paucity of research on classifications of DFS within the existing literature. Methods We reviewed 183 DFS patients aged 24 to 82 years treated for various foot deformities between 2015 to 2018. Results Analysis of clinical studies allowed us to systematize deformities of the distal segments of lower limbs in DFS patients. DFS related foot deformities were classified; clinical and radiological classification of foot deformities caused by Charcot neuro-osteoarthropathy (CN) developed and amendments to the generally accepted classifications of DFS with emphasis on the orthopedic management offered. Discussion Lack of a clear understanding of locomotor function disorders, staging of clinical, radiological and anatomical changes in the foot bones at different stages of the disease strongly influence on the potential for multidisciplinary collaborative practice (endocrinologists, surgeons and orthopedists) to ensure an optimal clinical outcome, and an orthopedist may even refuse to treat. The approaches we offered for classification of DFS and foot deformities are different from the known ones and are made from the perspective of the orthopedic and trauma surgeon whose service is rarely used for the treatment of DFS patients in Russia. Conclusion The orthopaedic classification of DFS offered can be helpful in determining the optimal surgical treatment, predicting the course of the pathological process and the functional outcome.
\end{abstract}

Keywords: diabetic foot, foot deformities, classification

\section{INTRODUCTION}

Peripheral neuropathy and angiopathy are associated with the pathogenesis of diabetic foot syndrome (DFS) [1, 2]. Generally accepted classification of DFS is based on the pathogenesis of the disease and includes four types: neuropathic (trophic ulcer), neuropathic (Charcot neuroosteoarthropathy (CN)), neuro-ischemic and ischemic conditions [3]. Russian statistical report of 2013-2016 indicated to nearly $90 \%$ of patients suffering from peripheral neuropathy of lower limbs [4]. For many years in Russia, endocrinologists and surgeons were mostly involved in the management of DFS providing care for purulent-necrotic conditions and vascular diseases while orthopeadic and joint replacement surgeons took care of more advanced stages of DFS.

\section{MATERIAL AND METHODS}

We reviewed 183 DFS patients aged 24 to 82 years treated for various foot deformities between 2015 to 2018. There were 109 female and 74 male patients. Surgical treatment of foot deformities was performed for 52 patients, including 25 males and 27 females aged 24 to 75 years. Type 2 diabetes mellitus was diagnosed in 47 patients who suffered from the condition from 1 year to 15 years. Type 1 insulindependent diabetes was diagnosed in 5 patients who suffered from the disease from 10 to 17 years.

\section{RESULTS}

Workup of patients included physical examination performed by an orthopedic and trauma surgeon, standard radiological assessment and allowed for grouping several types of DFS related foot deformities.

Type I. Primary deformity:

- without amputation and without CN.
Type II. Secondary deformity:

- without amputation, CN and foot deformity;

- post amputation, without CN;

- post amputation, CN and foot deformity.

I. Primary deformities unrelated to DFS/not caused by DFS are common static deformities of the forefoot featuring valgus alignment of the great toe,

[arshikov M.V., Bardiugov P.S., Yarygin N.V. Orthopaedic aspects of diabetic foot syndrome classifications. Genij Ortopedii, 2020, vol. 26, no 2, pp. 173-178. DOI 10.18019/1028-4427-2020-26-2-173-178 
hammer toes deformity, transverse flatness (Fig. 1 a) or hyperarch of the forefoot (Fig. 1 b), Tailor's bunion deformity; posttraumatic deformities, congenital deformities, limb shortening, etc. The extent of the deformity can vary and be determined using the existing orthopaedic classifications with appropriate radiological characterization. Primary deformity was observed in $38 \%(n=69)$ of the cases.
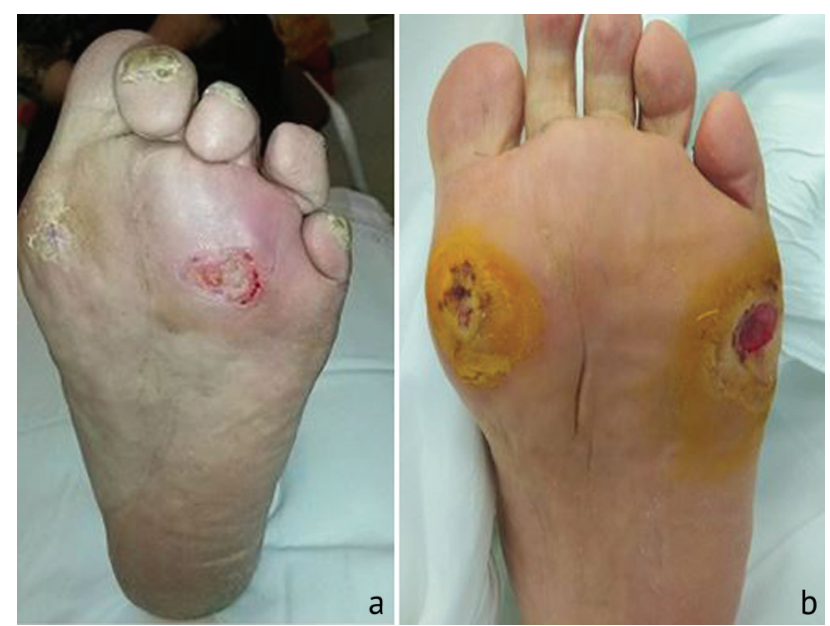

Fig.1 The right foot of a 56-year-old patient K. showing transverse flatness and an ulcer on the plantar aspect of the head of the third metatarsal $(\boldsymbol{a})$; the foot of a 52-yearold patient S. showing hyperarch of the forefoot and ulcers on the plantar surface at the heads of the first and fifth metatarsals $(\boldsymbol{b})$

II. Secondary deformities associated with DFS were detected in $62 \%$ of the cases $(n=114)$. From them, $21 \%$ of patients $(n=38)$ were amputees, had $\mathrm{CN}$ and a deformity.

Two types of secondary deformities that are most common occur in the midfoot (Lisfranc, Chopart joints) and the hindfoot (subtalar joint and calcaneus, ankle joint).

Hindfoot deformities are graded as follows,

Grade 1: varus/valgus alignment of calcanealtibial angle of not more that 20 degrees with plantigrade foot. Body weight is borne by the whole plantar surface at the gait. Radiological signs of avascular necrosis can reveal mild bone displacement;

Grade 2: varus/valgus alignment of calcanealtibial angle of 20 to 40 degress with slightly impaired supportability of the limb; the patient would normally use additional means of support. Body weight is often borne by the plantar surface and some other aspects of the foot that can lead to a neuropathic ulcer under the pressure. Radiographs show subluxations, partial avascular necrosis of the heel or the talus;
Grade 3: varus/valgus alignment of calcaneal-tibial angle of more than 40 degress with severely impaired supportability of the limb; patients are unable to walk unassisted and need either crutches or wheelchair for ambulation. Body weight is normally borne by the lateral surface of the foot and neuropathic ulcer are normally seen. Radiographs show subluxations or displacments, severe destruction of the heel or the talus, and the tibial, fibular epiphysis (Fig. 2).

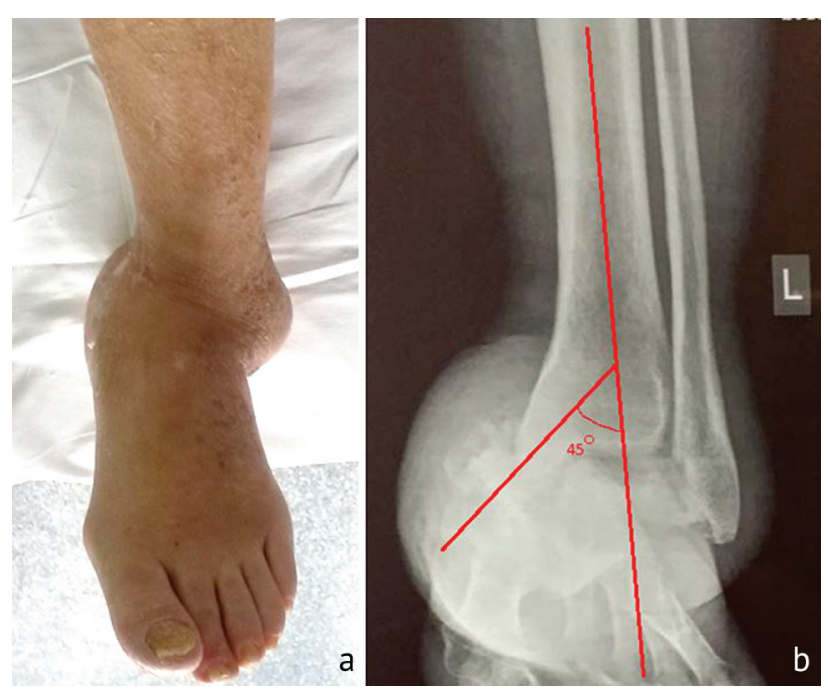

Fig. $2 \mathrm{CN}$ foot of a 53-year-old patient M. showing varus alignment of more than 40 degrees

Midfoot deformities are characterized by prolapse of the tarsal bones, valgus alignment of the forefoot and graded as follows:

Grade 1:

a) flat foot; decreased height of the longitudinal arch of the foot with an inflection angle (formed by three points: calcaneal attachment of the plantar fascia, the head of a less dorsally displaced metatarsal and plantar surface of the most prominent midfoot bone) measuring 160 to 180 degrees; mild or moderate destruction and displacement of bones forming Lisfranc, Chopart joints (signs of osteoporosis, erosion of the articular surfaces, periosteal reaction and microfractures) seen radiologically;

b) presence of a prominent bone fragment; mild or moderate decrease in the height of the longitudinal arch, an inflection angle of 160 degrees or less; destruction of bones forming Lisfranc, Chopart joints being not evident; presence of pathologically prominent bone part/bones forming Lisfranc, Chopart joints due to subluxation anywhere seen radiologically and clinically (Fig. 3). 


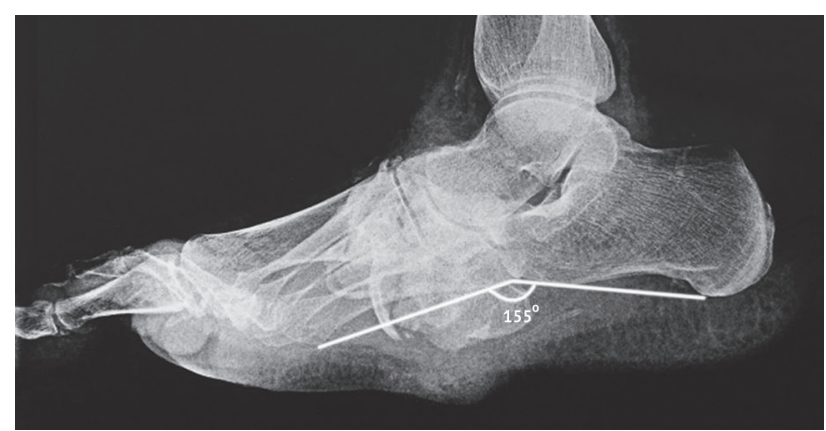

Fig. $3 \mathrm{CN}$ foot showing midfoot deformity developed due to partial avascular necrosis of the tarsal bones, subluxated cuboid with maintained height of the longitudinal arch

Supportability of the limb is normally intact. Neuropathic ulcers are not common. Walking aids are rarely needed.

\section{Grade 2:}

a) flat foot and presence of a prominent bone fragment; considerably decreased or absent height of the longitudinal arch with an inflection angle of 160 to 180 degrees seen radiologically; presence of pathologically prominent bone part/bones forming Lisfranc, Chopart joints due to subluxation or displacement observed clinically; moderate bone destruction (bone fractures and dislocations, subluxations, lesion of $1 / 3$ of the bone);

b) rocker bottom foot; the height of the longitudinal arch showing negative values with an inflection angle of more than 180 degrees; evident destruction of bones forming Lisfranc or Chopart joints (lesion of more than $1 / 3$ of the bone volume), fractures and considerably displaced bone fragments anywhere, bone subluxations/dislocations (Fig. 4).

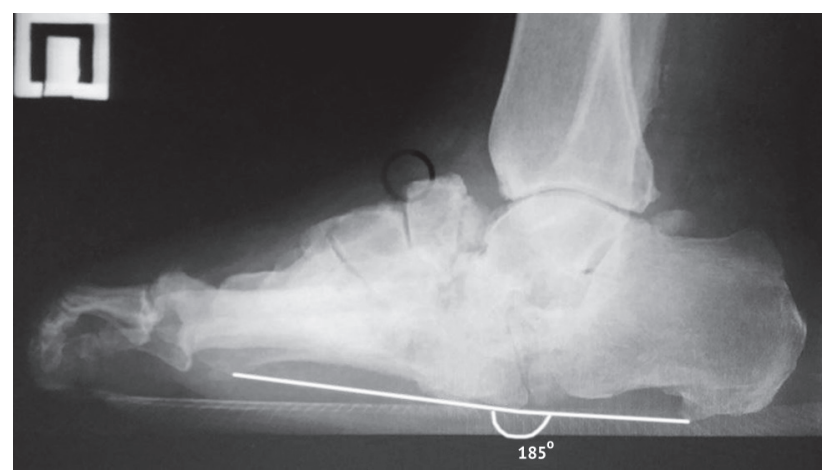

Fig. $4 \mathrm{CN}$ foot showing pathological fractures, destruction of the midfoot bones resulting in rocker bottom deformity

Supportability of the limb is limited. Neuropathic ulcers are common. Patients have to use additional means of support.

\section{Grade 3:}

Rocker bottom foot and presence of a prominent bone fragment; radiological height of the longitudinal arch showing negative values with an inflection angle measuring more than 180 degrees; evident destruction of bones forming Lisfranc/Chopart joints (lesion of more than $1 / 3$ of the bone volume), fractures and considerably displaced bone fragments anywhere, bone subluxations/dislocations; presence of pathologically prominent bone parts/bones forming Lisfranc, Chopart joints due to bone subluxations or dislocations (Fig. 5).

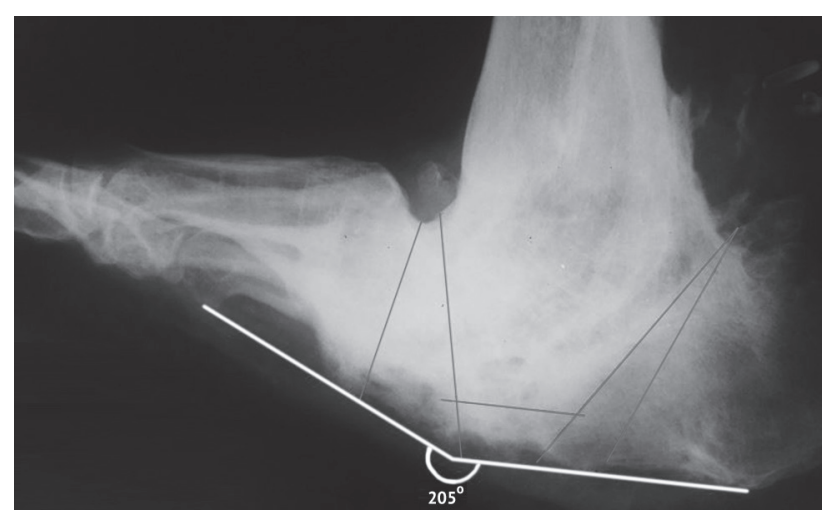

Fig. $5 \mathrm{CN}$ foot showing pathological fractures, destruction of the midfoot, hindfoot and ankle joint, ankylosis, rocker bottom deformity and prominent tarsal bones seen on the plantar surface of the foot

Supportability of the limb is decreased. Neuropathic ulcers are observed in the majority of cases. Patients have to use walking aids.

It should be noted that supportability of the limb iscan be expected to be better with the involvement of the midfoot as compared to that of the hindfoot, and most severe deformities are noted to develop in patients with involved midfoot and the hindfoot.

Post amputation without CN foot: 63 patients (34\%) of the study group.

Deformity resulting from minor amputations (postamputation foot deformities):

Grade 1: post exarticulation of toes resulting in greater pressure at the heads of metatarsals and often with neuropathic ulcers.

Grade 2: post amputation of a toe and resection of the head of the adjoining metatarsal. Amputation of the great toe together with the head of the metatarsal results in transfer of the weight to the plantar surface of middle metatarsal bones or the stump of the first metatarsal (Fig. 6 a). Amputation of a middle toe together with the metatarsal head leads to progression 
of baseline static deformities of the forefoot with greater valgus alignment of the great toe, varus alignment of the fifth toe and greater pressure on the head of the fifth metatarsal and the neighbouring metatarsal heads. Amputation of the fifth toe and the adjoining metatarsal head results in greater pressure on the head of adjacent metatarsals. This leads to plantar hyperkeratosis lesions, preulcerative skin lesions and, finally, to neuropathic ulcers that appear to be more common after a minor amputation as compared to exarticulation of a toe. Supportabilibity of the limb is slightly disturbed in the case.
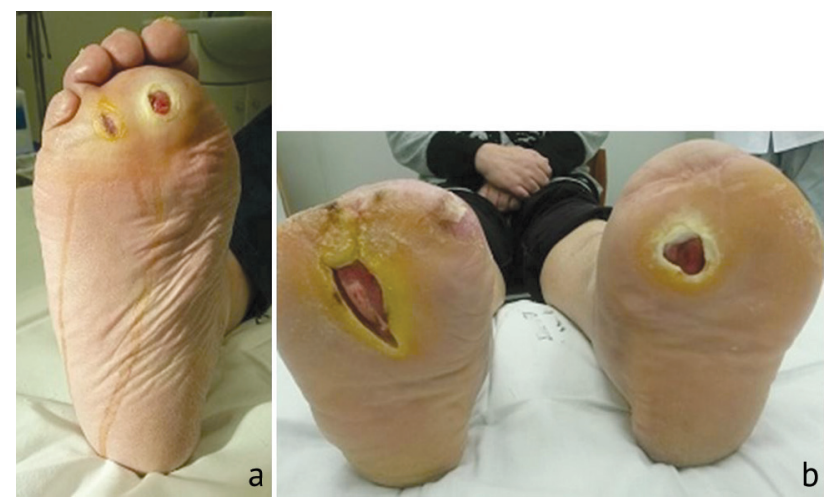

Fig. 6 Condition of the foot after amputation of the great toe and the adjoining metatarsal head with transfer of forces to the plantar aspect of the heads of the middle metatarsals $(\boldsymbol{a})$; condition after transmetatarsal resection at both feet resulting in equinus and greater pressure on the plantar aspect of the distal part of both stumps $(\boldsymbol{b})$

Grade 3: post transmetatarsal resection, exarticulation of the foot at the Chopart or Lisfranc joint. The load is sharply increasing on the plantar surface of the distal part of the foot stump and pathologically high pressure leads to hyperkeratosis lesions, preulceration with resultant ulcers. The foot appears malaligned because of equinus and intereferes with supportability of the limb and enhances the load on the plantar surface of the distal part of the stump leading to ulcers at the site (Fig. 6b). We have discovered that the greater volume of amptation is likely to result in neuropathic ulcers and disturbed supportability of the limb with the extremely high pressure being more difficult to correct at the site.

Post amputation, $\mathrm{CN}$ foot and deformity: 13 patients (7\%) of the study group.

The most severe type of pathology featuring a combination of lost functional support of the foot and $\mathrm{CN}$ foot deformity has less favorable prognosis for adequate correction to prevent new neuropathic ulcers. A pattern of disturbed supportability, radiological manifestations, the type and extent of $\mathrm{CN}$ foot deformity, a likelihood of neuropathic ulcer are determned with characteristics of secondary changes (grade II DFS related deformity) described above.

Our experience of treatment of DFS patients and associated foot deformities showed that the less the volume of foot amputation the more favorable and persistent the correction of high local pressure caused by deformity and the healing of neuropathic ulcers. The more the foot support maintained the easier the efforts needed to achieve a reliable outcome of surgical treatment with less likelihood of new neuropathic ulcers. Deformities of the hindfoot were shown to severely interefere with supportability of the limb being less vulnerable to both the nonoperative treatment for offloading plantar ulcers and less traumatic surgical management with resection of prominent bone $[5,6]$ and required reconstructive surgeries using internal or external osteosynthesis [7, 8, 9, 10]. Based of biomechanical analysis, routine diagnostic radiology and functional examination of the foot, as well as the experience from our foreign colleagues we devised the classification that may be useful for an orthopaedic surgeon in determining the optimal treatment strategy for an individual patient and also for any physician who is interested in the treatment of DFS. The classification of foot deformities we have developed and applied in clinical practice is presented in the Table.

Table

Classification of foot deformities related to DFS

\begin{tabular}{|c|c|c|c|c|}
\hline Type & \multicolumn{3}{|c|}{ Secondary deformities caused by DFS } & $\begin{array}{l}\text { Primary deformities } \\
\text { (unrelated to DFS) }\end{array}$ \\
\hline Type & Postamputation without CN & CN foot without amputation & $\mathrm{CN}$ foot + amputation & \multirow{3}{*}{$\begin{array}{l}\text { Generally accepted } \\
\text { orthopaedic } \\
\text { classifications of } \\
\text { foot deformities } \\
\text { unrelated to DFS }\end{array}$} \\
\hline \multirow[t]{2}{*}{ Grade } & \multirow{2}{*}{$\begin{array}{l}\text { I: exarticulation of a toe } \\
\text { II: amputation of toe }(s) \text { with } \\
\quad \text { adjoining metatarsal head }(s) \\
\text { III: resection of the forefoot }\end{array}$} & \multicolumn{2}{|c|}{$\begin{array}{l}\text { Hindfoot } \\
\text { I: malalignment of calcaneal-tibial angle of less than } 20^{\circ} \\
\text { II: malalignment of calcaneal-tibial angle of more than } 20^{\circ} \text { and } \\
\text { less than } 40^{\circ} \\
\text { III: malalignment of calcaneal-tibial angle of more than } 40^{\circ}\end{array}$} & \\
\hline & & \multicolumn{2}{|c|}{$\begin{array}{l}\text { Midfoot } \\
\text { I: a) flat foot; b) prominent bone fragment } \\
\text { II: a) flat foot + prominent bone fragment; b) rocker bottom foot } \\
\text { III: rocker bottom foot + prominent bone fragment }\end{array}$} & \\
\hline
\end{tabular}




\section{DISCUSSION}

There is a paucity of publications reporting dynamics in bone and joint changes with progression of pathological process in DFS patients, and specific features of orthopaedic status. There are no consistent classifications describing orthopaedic problems of DFS patients that would be helpful for the physician in identifying the optimal treatment strategy $[11,12,13]$.

There are many classification systems of DFS described in the medical literature. One of the most commonly cited diabetic wound classification systems was developed by Wagner and is based mainly on the involvement of tissues in ulcer-necrotic process [14]. The Infectious Diseases Society of America (IDSA)'s foot infection classification system [15] categorizes DFS by severity of foot infections. The University of Texas Diabetic Foot Classification [16] includes such comorbid factors as ischemia and infection to classify an ulcer. The Perfusion, Extent, Depth, Infection and Sensation (PEDIS) classification system defines DFS in comprehensive parameters with no deformities specified [17]. The University of Texas system is deemed to be useful and practical for the orthopaedic surgeon and we used it early in our work [18] for assessment of foot deformities in DFS patients but the system does not differentiate between the types of limb deformities as an imporatnt criteria for the choice of treatment strategy, rehabilitation and prognosis.

Diabetic neuro-osteoarthropathy (Charcot-foot) as a form of DFS is defined as non-infectious destruction of bone and joint(s) associated with diabetic neuropathy (International Working Group on the Diabetic Foot, 1999). The prevalence of Charcot foot in a general diabetic population is estimated between 0.1 and $7.5 \%$ [19]. The most commonly referenced classifications of Charcot's arthopathy include the Eichenholtz's radiographic classification [20] and classification offered by Armstrong D.G. [21] which relies on clinical and x-ray findings. The latter classification and the modified version based on clinical and MRI findings [22] fail to identify location and extent of the deformity. A descriptive anatomical classification of the Charcot foot based on patterns of bone and joint destruction was described by Sanders L.J. and Frykberg R.G. in 1991 [23]. Although the approach to classification does not indicate the stage of disease, it more precisely identifies anatomical sites of involvement. Rogers et al. propose a new classification that accounts for the degree of complications in the Charcot joint. The system considers deformity, ulceration, and osteomyelitis, which may help to predict amputation [24]. The authors presented the hallmarks for diagnosis of $\mathrm{CN}$ only neglecting other types of deformities that encounter more often than Charcot foot. A. Eschler et al. reported positive long-term outcomes of organsaving treatment of $\mathrm{CN}$ in correlation with PEDIS classification. A favourable outcome in terms of overall complication, re-ulceration, and amputation rates for patients with a cumulative PEDIS count below 7 was found [25]. The classification does not consider location of the pathological process, other types of deformities but $\mathrm{CN}$ and their severity.

Lack of a clear understanding of locomotor function disorders, staging of clinical, radiological and anatomical changes in the foot bones at different stages of the disease strongly influence on the potential for multidisciplinary collaborative practice (endocrinologists, surgeons and orthopedists) to ensure an optimal clinical outcome, and an orthopedist may even refuse to treat. The approaches we offered for classification of DFS and foot deformities are different from the known ones and are made from the perspective of an orthopedic and trauma surgeon whose service is rarely used for the treatment of DFS patients in Russia.

\section{CONCLUSION}

With orthopaedic approaches to the treatment and prophylaxis of $\mathrm{CN}$, classifications that would define precisely the criteria necessary to make diagnoses are essential for practicing physician to facilitate interpretation of clinical and radiological findings and point to pathogenetic mechanisms and to links in the $\mathrm{CN}$ process. This can be helpful in determining the optimal surgical treatment, predicting the course of the pathological process and the functional outcome.

The authors declare that there is no conflict of interest.

The authors received no specific funding for this work. 


\section{REFERENCES}

1. Suntsov Iu.I., Bolotskaia L.L., Maslova O.V., Kazakov I.V. Epidemiologiia sakharnogo diabeta i prognoz ego rasprostranennosti v rossiiskoi federatsii [Epidemiology of diabetes mellitus and its prevalence prediction in the Russian Federation]. Sakharnyi Diabet, 2011, no. 1, pp. 15-18. (in Russian)

2. Izumi Y., Satterfield K., Lee S., Harkless L.B., Lavery L.A. Mortality of first-time amputees in diabetics: a 10-year observation. Diabetes Res. Clin. Pract., 2009, vol. 83, no. 1, pp. 126-131. DOI: 10.1016/j.diabres.2008.09.005.

3. Dedov I.I., Shestakova M.V., Maiorov A.Iu., eds. Algoritmy spetsializirovannoi meditsinskoi pomoshchi bolnym sakharnym diabetom. Vyp. 8 : Klinicheskie rekomendatsii [Algorithms for specialized medical care for patients with diabetes mellitus. Issue 8: Clinical recommendations]. Sakharnyi Diabet, 2017, vol. 20, no. 1S, pp. 6-110. (in Russian) DOI: 10.14341/DM20171S8.

4. Galstian G.R., Vikulova O.K., Isakov M.A., Zhelezniakova A.V., Serkov A.A., Egorova D.N., Artemova E.V., Shestakova M.V., Dedov I.I. Epidemiologiia sindroma diabeticheskoi stopy i amputatsii nizhnikh konechnostei v Rossiiskoi Federatsii po dannym Federalnogo Registra bolnykh sakharnym diabetom (2013-2016 gg.) [Epidemiology of the diabetic foot syndrome and the lower limb amputations in the Russian Federation by the data of Federal Register of patients with diabetes mellitus (2013-2016)]. Sakharnyi Diabet, 2018, vol. 21, no. 3, pp. 170-177. (in Russian) DOI: 10.14341/DM9688.

5. Udovichenko O.V., Grekova N.M. Diabeticheskaia stopa [Diabetic foot]. M., Prakticheskaia Meditsina, 2010, pp. $223-236$. (in Russian)

6. Myerson M.S. Surgery for the neuropathic foot and ankle. In: Reconstructive Foot and Ankle Surgery. Management of Complications. $2^{\text {nd }}$ ed. Philadelphia, Saunders. 2010. Chapter 14. P. 141 -158. DOI: 10.1016/C2009-0-32553-2.

7. Belczyk R.J., Rogers L.C., Andros G., Wukich D.K., Burns P.R. External fixation techniques for plastic and reconstructive surgery of the diabetic foot. Clin. Podiatr. Med. Surg., 2011, vol. 28, no. 4, pp. 649-660. DOI: 10.1016/j.cpm.2011.07.001.

8. Wiewiorski M., Yasui T., Miska M., Frigg A., Valderrabano V. Solid bolt fixation of the medial column in Charcot midfoot arthropathy. J. Foot Ankle Surg., 2013, vol. 52, no. 1, pp. 88-94. DOI:10.1053/j.jfas.2012.05.017.

9. Stapleton J.J., Zgonis T. Surgical reconstruction of the diabetic Charcot foot: internal, external or combined fixation? Clin. Podiatr. Med. Surg., 2012, vol . 29, no. 3, pp. 425-33. DOI: 10.1016/j.cpm.2012.04.003.

10.Capobianco C.M., Ramanujam C.L., Zgonis T. Charcot foot reconstruction with combined internal and external fixation: case report. J. Orthop. Surg. Res., 2010, no. 5, pp. 7. DOI: 10.1186/1749-799x-5-7.

11.Schade V.L., Andersen C.A. A literature-based guide to the conservative and surgical management of the acute Charcot foot and ankle. Diabet. Foot Ankle, 2015, vol. 6, pp. 10. DOI :10.3402/dfa.v6.26627.

12.Obolenskii V.N., Protsko V.G., Komeliagina E.Iu. K voprosu o klassifikatsii sindroma diabeticheskoi stopy [The problem of classification of the diabetic foot syndrome]. Khirurg, 2016, no. 10, pp. 37-47. (in Russian)

13.Papanas N., Maltezos E. Etiology, pathophysiology and classifications of the diabetic Charcot foot. Diabet. Foot Ankle, 2013, no. 4, pp. 20872. DOI: 10.3402/dfa.v4i0.20872.

14.Wagner F.M. Jr. A classification and treatment program for diabetic, neuropathic and dysvascular foot problems. Instr. Course Lect., 1979, vol. 28, pp. 143-165. DOI:10.1177/107110079001100211.

15.Lipsky B.A., Berendt A.R., Cornia P.B., Pile J.C., Peters E.J.G., Armstrong D.G., Deery H.G., Embil J.M., Joseph W.S., Karchmer A.W., Pinzur M.S., Senneville E. Infectious Diseases Society of America. Clinical Practice Guideline for the diagnosis and treatment of diabetic foot infections. J. Am. Podiatr. Med. Assoc., 2013, vol. 103, no. 1, pp. 2-7. DOI: 10.7547/1030002.

16.Lavaery L.A., Armstrong D.G., Harkless L.B. Classification of diabetic foot wounds. Foot Ankle Surg., 1996, vol. 35, no. 6, pp. 528531. DOI:10.1016/s1067-2516(96)80125-6.

17.Schaper N.C. Diabetic foot ulcer classification system for research purposes: a progress report on criteria for including patients in research studies. Diabetes Metab. Res. Rev., 2004, vol. 20, no. Suppl. 1, pp. S90-S95. DOI: 10.1002/dmrr.464.

18.Armstrong D.G. The University of Texas Diabetic Foot Classification System. Ostomy Wound Manage, 1996, vol. 42, no. 8, pp. 60-61.

19.Ergen F.B., Sanverdi S.E., Oznur A. Charcot foot in diabetes and an update on imaging. Diabet. Foot Ankle, 2013, vol. 4, no. 1, pp. 21884. DOI: $10.3402 /$ dfa.v4i0.21884.

20.Eichenholtz S.N. Charcot Joints. Springfield, IL, USA, Charles C. Thomas, 1966.

21.Armstrong D.G., Todd W.F., Lavery L.A., Harkless L.B., Bushman T.R. The natural history of acute Charcot's arthropathy in a diabetic foot specialty clinic. J. Am. Podiatr. Med. Assoc., 1997, vol. 87, no. 6, pp. 357-363. DOI:10.7547/87507315-87-6-272.

22.Chantelau E.A., Grützner G. Is the Eichenholtz classification still valid for the diabetic Charcot foot? Swiss Med. Wkly., 2014, pp. 144. DOI: 10.4414/smw.2014.13948.

23.Sanders L.J., Frykberg R.G. Diabetic neuropathic osteoarthropathy: the Charcot foot. In: Frykberg R.G., ed. The high risk foot in diabetes mellitus. New York, NY, Churchill Livingstone, 1991, pp. 297-338.

24.Rogers L.C., Bevilacqua N.J. The diagnosis of Charcot foot. Clin. Podiatr. Med. Surg., 2008, vol. 25, no. 1, pp. 43-51. DOI: 10.1016/j. cpm.2007.10.006.

25.Eschler A., Gradl G., Wussow A., Mittlmeier T. Prediction of complications in a high-risk cohort of patients undergoing corrective arthrodesis of late stage Charcot deformity based on the PEDIS score. BMC Musculoskelet. Disord., 2015, vol. 16, pp. 349. DOI: 10.1186/s12891-015-0809-6.

Received: 23.09.2019

\section{Information about the authors:}

1. Mikhail V. Parshikov, M.D., Ph.D., Professor,

A.I. Yevdokimov Moscow State University of Medicine and Dentistry, Moscow, Russian Federation

2. Petr S. Bardiugov,

A.I. Yevdokimov Moscow State University of Medicine and Dentistry, Moscow, Russian Federation,

Email: petrbardiugov@gmail.com

3. Nikolai V. Yarygin, M.D., Ph.D., Corresponding Member of RAS, Professor,

A.I. Yevdokimov Moscow State University of Medicine and Dentistry, Moscow, Russian Federation 